Journal of Case Reports 2018;8(4):286-289

\title{
A Massive Pleomorphic Adenoma Arising from the Submandibular Gland
}

\author{
Daniel Lee John Bunker, Rebecca Kate Nothrop, Amanda Young \\ Department of General Surgery, Launceston General Hospital, Launceston, Tasmania, Australia.
}

\author{
Corresponding Author: \\ Dr. Daniel Lee John Bunker \\ Email: danielljbunker@gmail.com \\ This is an Open Access article distributed \\ under the terms of the Creative Commons \\ Attribution License (creativecommons.org/ \\ licenses/by/3.0). \\ Received \\ Accepted \\ Published
}

\begin{abstract}
Background: Salivary gland neoplasms are relatively rare tumors of the head and neck, with large tumors being extremely uncommon. Case Report: We report the first published case in the Western World of a massive pleomorphic adenoma of the submandibular gland. Conclusion: Such tumors need to be carefully assessed and treated with surgical excision as they harbour a risk for malignant degeneration. The potential for recurrence following resection mandates ongoing follow-up in this cohort of patients.
\end{abstract}

Keywords: Head, Humans, Neck, Pleomorphic Adenoma, Salivary Gland Neoplasms.

\section{Introduction}

Salivary gland neoplasms constitute a small proportion of all head and neck tumors. Of these, the most common is the pleomorphic adenoma, which usually arises from the parotid. Very large lesions arising from the submandibular gland are extremely rare. Due to their potential for malignant change, excision is recommended. We present a case of a massive pleomorphic adenoma of the submandibular gland in a 68 year old gentleman which was treated with local excision. This is the first report of such a case in the Western world.

\section{Case Report}

A 68-year-old man was referred to our surgical department with a painless right submandibular mass for assessment. He had a background of atrial fibrillation, hypertension and recurrent deep venous thrombosis. The mass had been present for approximately twenty years, slow growing and asymptomatic [Fig.1]. Due to its size, the patient was complaining of difficulty with putting on shirts and concerns regarding cosmesis. Clinically, a large, non-tender mass was present below the right jaw. It was mobile without any evidence of tethering to surrounding structures and no associated lymphadenopathy. A CT scan of the neck was performed and demonstrated a $66 \times 65 \mathrm{~mm}$ soft tissue mass containing multiple calcifications, with a low density centre (10 Hounsfield units). The mass abutted the right parotid and right submandibular glands, displacing the great vessels medially [Fig.2].

After informed consent he proceeded to surgical excision. Intra-operatively, the mass was noted to arise from the right submandibular gland. It was well-circumscribed and easily shelled from the surrounding structures. It was firm and nodular with ectatic capsular veins. A drain was inserted to prevent post-operative hematoma formation. Unfortunately, the drain lost suction on the ward and the patient needed to return to theatre on day one for an evacuation of hematoma (no bleeding point identified). Subsequent recovery was unremarkable.

Macroscopic cross-section of the tumor showed a glistening multi-lobulated mass with 


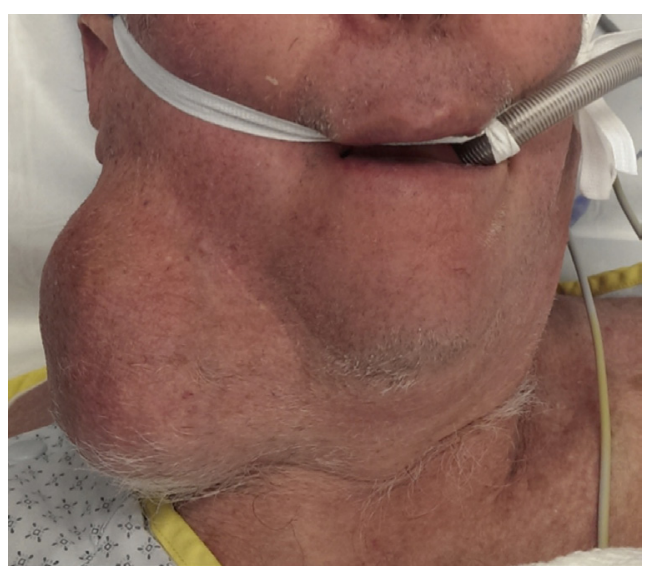

Fig.1: Pre-operative appearance.

a mucinous appearance and some minor central cystic change [Fig.3]. Haematoxylin and eosin staining revealed a fibromyxomatous stroma with trabeculae, strands of epithelial cells and focal cartilage, consistent with a pleomorphic adenoma of the submandibular gland [Fig.4]. Although resection margins appeared clear macroscopically, microscopic examination of the mass revealed patches where the tumor lobules breached the external capsule.

\section{Discussion}

Salivary gland neoplasms are relatively uncommon, accounting for approximately $3 \%$ of head and neck tumors, and are usually benign [1]. Of these, pleomorphic adenomas are the most common, compromising $70-90 \%$ of salivary gland tumors [2]. A 23-year retrospective study of 6,982 primary salivary gland tumors identified pleomorphic adenoma in $69 \%$ of cases. In this series, only $20 \%$ were located in the minor salivary glands [3]. Pleomorphic adenomas most commonly arise from the parotid gland (usually the superficial lobe): only $8-10 \%$ of pleomorphic adenomas occur primarily in the submandibular gland [4]. Interestingly, tumors arising from successively smaller salivary glands have an increased predilection for malignancy, with $50 \%$ of submandibular neoplasms being malignant.



Fig.2: Axial section throughneckshowinglarge heterogeneous mass with central hypo-density and peripheral calcifications.

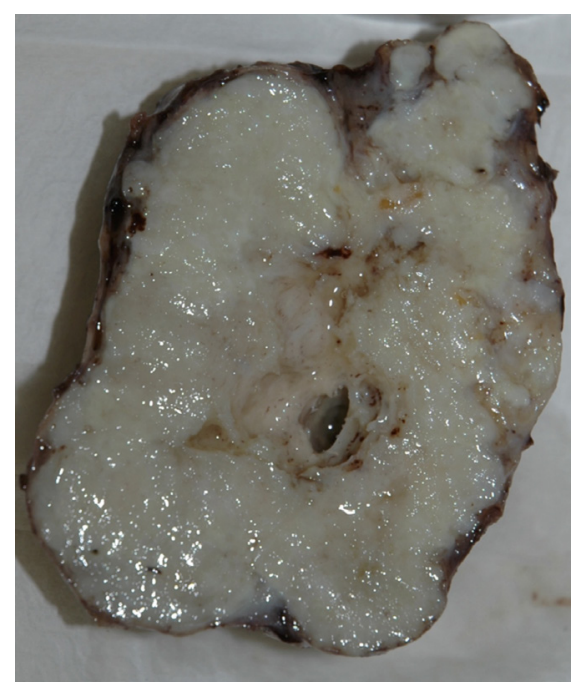

Fig.3: Macroscopic specimen displaying a mucinous appearance with areas of cystic change.



Fig.4: Fibromyxomatous stroma with focal cartilage and epithelial elements (Haematoxylin and eosin stain $\times 20$ ). 
Pleomorphic adenomas are sometimes referred to as 'benign mixed tumors' as they are comprised of epithelial, myoepitheial and mesenchymal (stromal) components. Whilst they appear to be encapsulated and well-circumscribed from the surrounding tissues intra-operatively, histology often reveals microscopic extensions of pseudo-capsule [5]. Remnants of pseudo-capsule, tumor spillage and incomplete excision explain the high rates of recurrence after surgical removal [6].

Clinically, they present as a painless, slowly growing mass in the middle-aged population. Occasionally they can reach large sizes leading to grotesque disfiguration. Those reaching large sizes usually arise from the parotid [7]. Very large pleomorphic adenomas arising from the submandibular gland have only rarely been reported, and never in the Western world [8-10]. Approximately $6 \%$ of pleomorphic adenomas can undergo malignant change, usually in the sixth or seventh decades of life [2]. The malignancies associated with pleomorphic adenomas include carcinoma ex-pleomorphic adenoma (malignant transformation), carcinosarcoma and metastasising mixed tumor.

It is difficult to differentiate between benign and malignant tumors on examination, although certain features such as pain, nerve palsies or associated lymphadenopathy should alert the clinician to the possibility of a primary malignancy or malignant transformation. Ultrasound-guided fine needle aspiration biopsy does not always provide conclusive distinction between benign and malignant lesions, placing importance on preoperative imaging. When malignancy is suspected or a lesion is palpable, MRI remains the imaging modality of choice as it gives superior information regarding invasive spread [11]. Invasion of deeper structures on imaging is particularly suggestive of metastatic potential, whilst tumor margins, homogeneity and signal intensity are not particularly helpful [11]. Benign pleomorphic adenomas usually present on MRI as a lesion with a defined border, decreased $\mathrm{T} 1$ and increased $\mathrm{T} 2$ signal intensities, moderate enhancement with contrast and possibly necrotic, hemorrhagic or cystic areas with calcification [2].

Treatment of benign lesions of the submandibular gland is by local excision. Malignant lesions require more extensive resection which is planned in conjunction with imaging findings. Post-operative recurrence depends on the surgical technique, and when it does occur is it often multiple and clustered, with the potential for malignant change (carcinoma ex-pleomorphic adenoma) and metastatic spread.

\section{Conclusion}

Although rare, tumors of the submandibular gland require careful evaluation by physical examination and imagining. Intra-operatively, care needs to be taken to avoid disruption of the capsule or tumor spillage to minimize the risk of recurrence. Clinical follow-up after excision is important to monitor for recurrent disease.

Contributors: DLJB: surgical registrar, manuscript writing; RKN: medical doctor, manuscript revision; AY: consultant surgeon and critical inputs into the manuscript. DLJB will act as a study guarantor. All authors approved the final version of this manuscript.

Funding: None; Competing interests: None stated.

\section{References}

1. Eveson JW, Cawson RA. Salivary gland tumours. A review of 2410 cases with particular reference to histological types, site, age and sex distribution. J Pathol. 1985;146:51-58.

2. Thoeny HC. Imaging of salivary gland tumours. Cancer Imaging. 2007; 7:52-62.

3. Tian Z, Li L, Wang L, Hu Y, Li J. Salivary gland neoplasms in oral and maxillofacial regions: a 23-year retrospective study of 6982 cases in an eastern Chinese population. Int J Oral Maxillofac Surg. 2010;39:235242.

4. Eneroth CM. Incidence and prognosis of salivarygland tumours at different sites. A study of parotid, submandibular and palatal tumours in 2632 patients. Acta Otolaryngol Suppl. 1969;263:174-178.

5. Stennert E, Guntinas-Lichius O, Klussmann JP, Arnold 
G. Histopathology of pleomorphic adenoma in the parotid gland: a prospective unselected series of 100 cases. Laryngoscope. 2001;111:2195-2200.

6. Stennert E, Wittekindt C, Klussmann JP, Arnold G, Guntinas-Lichius O. Recurrent pleomorphic adenoma of the parotid gland: a prospective histopathological and immunohistochemical study. Laryngoscope. 2004;114:158-163.

7. Kakimoto, N, Gamoh S, Tamaki J, Kishino M, Murakami S, Furukawa S. CT and MR images of pleomorphic adenoma in major and minor salivary glands. Eur $\mathrm{J}$ Radiol. 2009;69:464-472.

8. Rai S, Sodhi SP, Sandhu SV. Pleomorphic adenoma of submandibular gland: An uncommon occurrence. Natl J Maxillofac Surg. 2011;2:66-68.

9. Perumal CJ, Meyer M, Mohamed A. A giant pleomorphic adenoma of the submandibular salivary gland: a case report. Craniomaxillofac Trauma Reconstr, 2012;5:185188.

10. Verma S. A case of huge submandibular pleomorphic adenoma. The Internet Journal of Head and Neck Surgery. 2009;4(2)1-5.

11. Freling NJ, Molenaar WM, Vermey A, Mooyaart EL, Panders AK, Annyas AA, et al. Malignant parotid tumors: clinical use of MR imaging and histologic correlation. Radiology. 1992;185:691-696. 